\section{A Taxonomy of Illocutionary Acts}

\section{Introduction}

The primary purpose of this paper is to develop a reasoned classification of illocutionary acts into certain basic categories or types. It is to answer the question: How many kinds of illocutionary acts are there? Since any such attempt to develop a taxonomy must take into account Austin's classification of illocutionary acts into his five basic categories of verdictive, expositive, exercitive, behabitive, and commissive, a second purpose of this paper is to assess Austin's classification to show in what respects it is adequate and in what respects inadequate. Furthermore, since basic semantic differences are likely to have syntactical consequences, a third purpose of this paper is to show how these different basic illocutionary types are realized in the syntax of a natural language such as English.

In what follows, I shall presuppose a familiarity with the general pattern of analysis of illocutionary acts offered in such works as Austin, How to Do Things with Words, Searle, Speech Acts, and Searle, "Austin on Locutionary and Illocutionary Acts." ${ }^{1}$ In particular, I shall presuppose a distinction between the illocutionary force of an utterance and its propositional content as symbolized as $F(p)$. The aim of this paper then is to classify the different types of $F$.

\section{Different Types of Differences between Different Types of Illocutionary Acts}

Any taxonomical effort of this sort presupposes criteria for distinguishing one (kind of) illocutionary act from another. What are the criteria by which we can tell that of three actual utterances one is a report, one

1 J. L Austin, How to Do Things with Words (Oxford: Clarendon Press, 1962); J. R. Searle, Speech Acts: An Essay in the Philosophy of Language (London: Cambridge University Press, 1969); and J. R. Searle, "Austin on Locutionary and Illocutionary Acts," Philosophical Review, 1968. a prediction, and one a promisc? In order to develop higher order gen era, we must first know how the species promise, prediction, report, etc., differ one from another. When one attempts to answer that question one discovers that there are several quite different principles of distinction; that is, there are different kinds of differences that enable us to say that the force of this utterance is different from the force of that utterance. For this reason the metaphor of force in the expression "illocutionary force" is misleading since it suggests that different illocutionary forces occupy different positions on a single continuum of force. What is actually the case is that there are several distinct crisscrossing continua. A related source of confusion is that we are inclined to confuse illocutionary verbs with types of illocutionary acts. We are inclined, for example, to think that where we have two nonsynonymous illocutionary verbs they must necessarily mark two different kinds of illocutionary acts. In what follows, I shall try to keep a clear distinction between illocutionary verbs and illocutionary acts. Illocutions are a part of language as opposed to particular languages. Illocutionary verbs are always part of a particular language: French, German, English, or whatnot. Differences in illocutionary verbs are a good guide but by no means a sure guide to differences in illocutionary acts.

It seems to me there are (at least) twelve significant dimensions of variation in which illocutionary acts differ one from another and I shall - all too briskly - list them:

1. Differences in the point (or purpose) of the (type of) act. The point or purpose of an order can be specified by saying that it is an attempt to get the hearer to do something. The point or purpose of a description is that it is a representation (true or false, accurate or inaccurate) of how something is. The point or purpose of a promise is that it is an undertaking of an obligation by the speaker to do something. These differences correspond to the essential conditions in my analysis of illocutionary acts in Speech Acts. ${ }^{2}$ Ultimately, I believe, essential conditions form the best basis for a taxonomy, as I shall attempt to show. It is important to notice that the terminology of "point" or "purpose" is not meant to imply, nor is it based on the view, that every illocutionary act has a definitionally associated perlocutionary intent. For many, perhaps most, of the most important illocutionary acts, there is no essential perlocutionary intent associated by definition with the corre-

${ }^{3}$ Searle, Speech Acts, chap. 3. 
John R. Scarle

sponding verb, e.g., statements and promises are not by definition at tempts to produce perlocutionary effects in hearers.

The point or purpose of a type of illocution I shall call its illocutionary point. Illocutionary point is part of but not the same as illocutionary force. Thus, for example, the illocutionary point of a request is the same as that of a command: both are attempts to get hearers to do something. But the illocutionary forces are clearly different. In general, one can say that the notion of illocutionary force is the resultant of several elements of which illocutionary point is only one, though, I believe, the most important one.

2. Differences in the direction of fit between words and the world. Some illocutions have as part of their illocutionary point to get the words (more strictly, their propositional content) to match the world, others to get the world to match the words. Assertions are in the former category, promises and requests are in the latter. The best illustration of this distinction I know of is provided by Miss Anscombe. ${ }^{3}$ Suppose a man goes to the supermarket with a shopping list given him by his wife on which are written the words "beans, butter, bacon, and bread." Suppose as he goes around with his shopping cart selecting these items, he is followed by a detective who writes down everything he takes. As they emerge from the store both shopper and detective will have identical lists. But the function of the two lists will be quite different. In the case of the shopper's list, the purpose of the list is, so to speak, to get the world to match the words; the man is supposed to make his actions fit the list. In the case of the detective, the purpose of the list is to make the words match the world; the man is supposed to make the list fit the actions of the shopper. This can be further demonstrated by observing the role of a "mistake" in the two cases. If the detective gets home and suddenly realizes that the man bought pork chops instead of bacon, he can simply erase the word "bacon" and write "pork chops." But if the shopper gets home and his wife points out he has bought pork chops when he should have bought bacon, he cannot correct the mistake by erasing "bacon" from the list and writing "pork chops."

In these examples the list provides the propositional content of the illocution, and the illocutionary force determines how that content is supposed to relate to the world. I propose to call this difference a dif-

${ }^{3}$ G. E. M. Anscombe, Intentions (Oxford: Blackwell, 1957).

\section{A TAXONOMY OF ILLOCUTIONARY ACTS}

ference in direction of fit. 'The detective's list has the word to-world direction of fit (as do statements, descriptions, assertions, and explanations); the shopper's list has the world-to-word direction of fit (as do requests, commands, vows, promises). I represent the word-to-world direction of fit with a downward arrow thus $\downarrow$ and the world-to-word direction of fit with an upward arrow thus $\uparrow$. Direction of fit is always a consequence of illocutionary point. It would be very elegant if we could build our taxonomy entirely around this distinction in direction of fit, but though it will figure largely in our taxonomy, I am unable to make it the entire basis of the distinctions.

3. Differences in expressed psychological states. A man who states, explains, asserts, or claims that $p$ expresses the belief that $p$; a man who promises, vows, threatens, or pledges to do a expresses an intention to do a; a man who orders, commands, requests $H$ to do $A$ expresses a desire (want, wish) that $H$ do $A$; a man who apologizes for doing $A$ expresses regret at having done $A$; etc. In general, in the performance of any illocutionary act with a propositional content, the speaker expresses some attitude, state, etc., to that propositional content. Notice that this holds even if he is insincere, even if he does not have the belief, desire, intention, regret, or pleasure which he expresses, he nonetheless expresses a belief, desire, intention, regret, or pleasure in the performance of the speech act. This fact is marked linguistically by the fact that it is linguistically unacceptable (though not self-contradictory) to conjoin the explicit performative verb with the denial of the expressed psychological state. Thus one cannot say "I state that $p$ but do not believe that $p$," "I promise that $p$ but I do not intend that $p$," etc. Notice that this only holds in the first person performative use. One can say, "He stated that $p$ but didn't really believe that $p$," "I promised that $p$ but did not really intend to do it," etc. The psychological state expressed in the performance of the illocutionary act is the sincerity condition of the act, as analyzed in Speech Acts, chapter 3.

If one tries to do a classification of illocutionary acts based entirely on different expressed psychological states (differences in the sincerity condition), one can get quite a long way. Thus belief collects not only statements, assertions, remarks, and explanations, but also postulations, declarations, deductions, and arguments. Intention will collect promises, vows, threats, and pledges. Desire or want will collect requests, orders, commands, askings, prayers, pleadings, beggings, and entreaties. Pleasure 


\section{John R. Searlc}

doesn't collect quite so many - congratulations, felicitations, welcomes, and a few others.

In what follows, I shall symbolize the expressed psychological state with the capitalized initial letters of the corresponding verb, the " $B$ " for "believe," "W" for "want," " $I$ " for "intend," etc.

These three dimensions - illocutionary point, direction of fit, and sincerity condition - seem to me the most important, and I will build most of my taxonomy around them, but there are several others that need remarking.

4. Differences in the force or strength with which the illocutionary point is presented. Both "I suggest we go to the movies" and "I insist that we go to the movies" have the same illocutionary point, but it is presented with different strengths, analogously with "I solemnly swear that Bill stole the money" and "I guess Bill stole the money." Along the same dimension of illocutionary point or purpose there may be varying degrees of strength or commitment.

5. Differences in the status or position of the speaker and hearer as these bear on the illocutionary force of the utterance. If the general asks the private to clean up the room, that is in all likelihood a command or an order. If the private asks the general to clean up the room, that is likely to be a suggestion or proposal or request but not an order or command. This feature corresponds to one of the preparatory conditions in my analysis in Speech Acts, chapter 3.

6. Differences in the way the utterance relates to the interests of the speaker and the hearer. Consider, for example, the differences between boasts and laments, between congratulations and condolences. In these two pairs one hears the difference as being between what is or is not in the interests of the speaker and hearer respectively. This feature is another type of preparatory condition according to the analysis in Speech Acts.

7. Differences in relations to the rest of the discourse. Some performative expressions serve to relate the utterance to the rest of the discourse (and also to the surrounding context). Consider, e.g., "I reply," "I deduce," "I conclude," and "I object." These expressions serve to relate utterances to other utterances and to the surrounding context. The features they mark seem mostly to involve utterances within the class of statements. In addition to simply stating a proposition, one may state it by way of objecting to what someone else has said, by way of replying
A 'IAXONOMY OI' HLOOCUTIONARY ACIS

to an carlicr point, by way of deducing it from certain cvidentiary prem ises, etc. "Iowever," "moreover," and "therefore" also perform these discourse-relating functions.

8. Differences in propositional content that are determined by illocu tionary-force indicating devices. The differences, for example, between a report and a prediction involve the fact that a prediction must be about the future whereas a report can be about the past or present. These differences correspond to differences in propositional content conditions as explained in Speech Acts.

9. Differences between those acts that must always be speech acts, and those that can be, but need not be, performed as speech acts. One may classify things, for example, by saying "I classify this as an $A$ and this as a B." But one need not say anything at all in order to be classifying; one may simply throw all the $A$ 's in the $A$ box and all the $B$ 's in the $B$ box. Similarly with estimate, diagnose, and conclude. I may make estimates, give diagnoses, and draw conclusions in saying "I estimate," "I diagnose," and "I conclude," but in order to estimate, diagnose, or conclude it is not necessary to say anything at all. I may simply stand before a building and estimate its height, silently diagnose you as a marginal schizophrenic, or conclude that the man sitting next to me is quite drunk. In these cases, no speech act, not even an internal speech act, is necessary.

10. Differences between those acts that require extra-linguistic institutions for their performance and those that do not. There are a large number of illocutionary acts that require an extra-linguistic institution, and generally a special position by the speaker and the hearer within that institution in order for the act to be performed. Thus in order to bless, excommunicate, christen, pronounce guilty, call the base runner out bid three no-trump, or declare war, it is not sufficient for any old speaker to say to any old hearer "I bless," "I excommunicate," etc. One must have a position within an extra-linguistic institution. Austin sometimes talks as if he thought all illocutionary acts were like this, but plainly they are not. In order to make a statement that it is raining or promise to come and see you, I need only obey the rules of language. No extralinguistic institutions are required. This feature of certain speech acts, that they require extra-linguistic institutions, needs to be distinguished from feature 5 , the requirement of certain illocutionary acts that the speaker and possibly the hearer as well have a certain status. Extra- 
John R. Scarle

linguistic institutions often confer status in a way relevant to illocutionary force, but not all differences of status derive from institutions. Thus an armed robber in virtue of his possession of a gun may order as opposed to, e.g., request, entreat, or implore victims to raise their hands. But his status here does not derive from a position within an institution but from his possession of a weapon.

11. Differences between those acts where the corresponding illocutionary verb has a performative use and those where it does not. Most illocutionary verbs have performative uses-e.g., 'state', 'promise', 'order', 'conclude'. But one cannot perform acts of, e.g., boasting or threatening, by saying "I hereby boast," or "I hereby threaten." 4 Not all illocutionary verbs are performative verbs.

12. Differences in the style of performance of the illocutionary act. Some illocutionary verbs serve to mark what we might call the special style in which an illocutionary act is performed. Thus the difference between, for example, announcing and confiding need not involve any difference in illocutionary point or propositional content but only in the style of performance of the illocutionary act.

\section{Weaknesses in Austin's Taxonomy}

Austin advances his five categories very tentatively, more as a basis for discussion than as a set of established results. "I am not," he says, "putting any of this forward as in the very least definitive." 5 I think they form an excellent basis for discussion but I also think that the taxonomy needs to be seriously revised because it contains several weaknesses. Here are Austin's five categories:

Verdictives. These "consist in the delivering of a finding, official or unofficial, upon evidence or reasons as to value or fact so far as these are distinguishable." Examples of verbs in this class are: acquit, hold,

"There are other verbs in English which sound odd in the first person present. Consider "lurk" and "skulk." It is odd in answer to the question "What are you doing?" to say "I am lurking in the bushes" or "I am skulking today." The reason may be that both verbs involve a negative assessment and it is odd to give a negative assessment of what one is doing while voluntarily doing it. Perhaps a similar explanation will work for "boast" and "threaten," since they both also seem to contain an element of negative assessment. Notice that they are acceptable if embedded in some apologetic form, e.g., "I hope you won't mind if I boast about my new motorcycle."

${ }^{5}$ Austin, How to Do Things with Words, p. 151.
A TAXONOMY OF HLIOCUTIONARY ACTS

calculate, describe, analyze, estimate, date, rank, assess, characterize, and describe.

Exercitives. One of these "is the giving of a decision in favor of or against a certain course of action or advocacy of it," "a decision that something is to be so, as distinct from a judgment that it is so." Some examples are: order, command, direct, plead, beg, recommend, entreat, and advise. Request is also an obvious example, but Austin does not list it. As well as the above, Austin also lists: appoint, dismiss, nominate, veto, declare closed, declare open, as well as announce, warn, proclaim, and give.

Commissives. "The whole point of a commissive," Austin tells us, "is to commit the speaker to a certain course of action." Some of the obvious examples are: promise, vow, pledge, covenant, contract, guarantee, embrace, and swear.

Expositives "are used in acts of exposition involving the expounding of views, the conducting of arguments and the clarifying of usages and references." Austin gives many examples of these; among them are: affirm, deny, emphasize, illustrate, answer, report, accept, object to, concede, describe, class, identify, and call.

Behabitives. This class, with which Austin was very dissatisfied ("a shocker," he called it) "includes the notion of reaction to other people's behavior and fortunes and of attitudes and expressions of attitudes to someone else's past conduct or imminent conduct."

Among the examples Austin lists are: apologize, thank, deplore, commiserate, congratulate, felicitate, welcome, applaud, criticize, bless, curse, toast, and drink. But also, curiously: dare, defy, protest, and challenge.

The first thing to notice about these lists is that they are not classifications of illocutionary acts but of English illocutionary verbs. Austin seems to assume that a classification of different verbs is eo ipso a classification of kinds of illocutionary acts, that any two nonsynonymous verbs must mark different illocutionary acts. But there is no reason to suppose that this is the case. As we shall see, some verbs, for example, mark the manner in which an illocutionary act is performed, e.g., "announce." One may announce orders, promises, and reports, but announcing is not on all fours with ordering, promising, and reporting. Announcing, to anticipate a bit, is not the name of a type of illocutionary act, but of the way in which some illocutionary act is performed. An announcement is never just an announcement because "announcing" is not the name 
John R. Scarle

of an illocutionary point. An announcement must also be a statement, order, etc.

Even granting that the lists are of illocutionary verbs and not necessarily of different illocutionary acts, it seems to me one can level the following additional criticisms against it.

1. First, a minor cavil, but one worth noting. Not all of the verbs listed are even illocutionary verbs. For example, "sympathize," "regard as," "mean to," "intend," and "shall." Take "intend": it is clearly not performative. Saying "I intend" is not intending; nor in the third person does it name an illocutionary act: "He intended . . ." does not report a speech act. Of course there is an illocutionary act of expressing an intention, but the illocutionary verb phrase is "express an intention," not "intend." Intending is never a speech act; expressing an intention usually, but not always, is.

2. The most important weakness of the taxonomy is simply this. There is no clear or consistent principle or set of principles on the basis of which the taxonomy is constructed. Only in the case of commissives has Austin clearly and unambiguously used illocutionary point as the basis of the definition of a category. Expositives, insofar as the characterization is clear, seem to be defined in terms of discourse relations (my feature 7). Exercitives seem to be at least partly defined in terms of the exercise of authority. Both considerations of status (my feature 5) as well as institutional considerations (my feature 10) are lurking in it. Behabitives do not seem to me at all well defined (as Austin, I am sure, would have agreed) but it seems to involve notions of what is good or bad for the speaker and hearer (my feature 6) as well as expressions of attitudes (my feature 3)

3. Because there is no clear principle of classification and because there is a persistent confusion between illocutionary acts and illocutionary verbs, there is a great deal of overlap from one category to another and a great deal of heterogeneity within some of the categories. The problem is not that there are borderline cases - any taxonomy that deals with the real world is likely to come up with borderline cases - nor is it merely that a few unusual cases will have the defining characteristics of more than one category. Rather a very large number of verbs find themselves smack in the middle of two competing categories because the principles of classification are unsystematic. Consider, for example, the verb "describe," a very important verb in anybody's theory of speech
A TAXONOMY OH HLLOCUTIONARY AC'TS

acts. Austin lists it as both a verdictive and an expositive. Given his definitions, it is casy to sec why: describing can be both the delivering of a finding and an act of exposition. But then any "act of exposition involving the expounding of views" could also in his rather special sense be "the delivering of a finding, official or unofficial, upon evidence or reasons." And indeed, a look at his list of expositives (pp. 161-162) is sufficient to show that most of his verbs fit his definition of verdictives as well as does "describe." Consider "affirm," "deny," "state," "class," "identify," "conclude," and "deduce." All of these are listed as expositives, but they could just as easily have been listed as verdictives. The few cases which are clearly not verdictives are cases where the meaning of the verb has purely to do with discourse relations, e.g., "begin by," "turn to," or where there is no question of evidence or reasons, e.g., "postulate," "neglect," "call," and "define." But then that is really not sufficient to warrant a separate category, especially since many of these "begin by," "turn to," "neglect" - are not names of illocutionary acts at all.

4. Not only is there too much overlap from one category to the next, but within some of the categories there are quite distinct kinds of verbs. Thus Austin lists "dare," "defy," and "challenge" alongside "thank," "apologize," "deplore," and "welcome" as behabitives. But "dare," "defy," and "challenge" have to do with the hearer's subsequent actions; they belong with "order," "command," and "forbid" both on syntactical and semantic grounds, as I shall argue later. But when we look for the family that includes "order," "command," and "urge," we find these are listed as exercitives alongside "veto," "hire," and "demote." But these, again as I shall argue later, are in two quite distinct categories.

5. Related to these objections is the further difficulty that not all of the verbs listed within the classes really satisfy the definitions given, even if we take the definitions in the rather loose and suggestive manner that Austin clearly intends. Thus nominating, appointing, and excommunicating are not the "giving of a decision in favor of or against a certain course of action," much less are they "advocating" it. Rather they are, as Austin himself might have said, performances of these actions, not advocacies of anything. That is, in the sense in which we might agree that ordering, commanding, and urging someone to do something are all cases of advocating that he do it, we cannot also agree that nominating or appointing is also advocating. When I appoint you 
John R. Searle

chairman, I don't advocate that you be or become chairman; I make you chairman.

In sum, there are (at least) the following six related difficulties with Austin's taxonomy. In ascending order of importance, there is a persistent confusion between verbs and acts; not all the verbs are illocutionary verbs; there is too much overlap of the categories; there is too much heterogeneity within the categories; many of the verbs listed in the categories don't satisfy the definition given for the category; and, most important, there is no consistent principle of classification.

I don't believe I have fully substantiated all six of these charges and I will not attempt to do so within the confines of this paper, which has other aims. I believe, however, that my doubts about Austin's taxonomy will have greater clarity and force after I have presented an alternative. What I propose to do is take illocutionary point and its corollaries, direction of fit and expressed sincerity conditions, as the basis for constructing a classification. In such a classification, other features - the role of authority, discourse relations, etc. - will fall into their appropriate places.

\section{Alternative Taxonomy}

In this section I shall present a list of what I regard as the basic categories of illocutionary acts. In so doing, I shall discuss briefly how my classification relates to Austin's.

Representatives. The point or purpose of the members of the representative class is to commit the speaker (in varying degrees) to something's being the case, to the truth of the expressed proposition. All of the members of the representative class are assessable on the dimension of assessment which includes true and false. Using Frege's assertion sign to mark the illocutionary point common to all the members of this class and the symbols introduced above, we may symbolize this class as follows:

$$
\vdash \downarrow B(p)
$$

The direction of fit is words-to-the-world; and the psychological state expressed is belief (that $p$ ). It is important to emphasize that words such as "belief" and "commitment" are here intended to mark dimen. sions; they are so to speak determinables rather than determinates. Thus there is a difference between suggesting that $p$ or putting it forward as : hypothesis that $p$ on the one hand, and insisting that $p$ or solemnly swear
A TAXONOMY OF ILLOCUTIONARY ACTS

ing that $p$ on the other. 'The degree of belief and commitment may ap proach or even reach zero, but it is clcar or will become clear that hypothesizing that $p$ and flatly stating that $p$ are in the same line of business in a way that neither is like requesting. Once we recognize the existence of representatives as a quite separate class, based on the notion of illocutionary point, then the existence of a large number of performative verbs denoting illocutions that seem to be assessable in the truefalse dimension and yet are not just "statements" will be easily explicable in terms of the fact that they mark features of illocutionary force which are in addition to illocutionary point. Thus, for example, consider "boast" and "complain." They both denote representatives with the added feature that they have something to do with the interest of the speaker (feature 6 above). "Conclude" and "deduce" are also representatives with the added feature that they mark certain relations between the representative illocutionary act and the rest of the discourse or the context of utterance (feature 7 above). This class will contain most of Austin's expositives as well as many of his verdictives for the, by now I hope obvious, reason that they all have the same illocutionary point and differ only in other features of illocutionary force. The simplest test of a representative is this: can you literally characterize it (inter alia) as true or false. Though I hasten to add that this will give neither necessary nor sufficient conditions, as we shall see when we get to my fifth class.

These points about representatives will, I hope, be clearer when I discuss my second class which, with some reluctance, I will call

Directives. The illocutionary point of these consists in the fact that they are attempts (of varying degrees, and hence more precisely, they are determinates of the determinable which includes attempting) by the speaker to get the hearer to do something. They may be very modest "attempts," as when I invite you to do it or suggest that you do it, or they may be very fierce attempts as when I insist that you do it. Using the exclamation mark as the illocutionary-point indicating device for the members of this class generally, we have the following symbolism:

$$
! \uparrow W(H \text { does } A)
$$

The direction of fit is world-to-words and the sincerity condition is want (or wish or desire). The propositional content is always that the hearer $H$ does some future action $A$. Verbs denoting members of this class are 


\section{John R. Searlc}

order, command, request, ask, question, ${ }^{6} \mathrm{beg}$, plead, pray, entreat, and also invite, permit, and advise. I think also that it is clear that dare, defy, and challenge which Austin lists as behabitives are in this class. Many of Austin's exercitives are also in this class.

Commissives. Austin's definition of commissives seems to me unexceptionable, and I will simply appropriate it as it stands with the cavil that several of the verbs he lists as commissive verbs do not belong in this class at all, such as "shall," "intend," "favor," and others. Commissives then are those illocutionary acts whose point is to commit the speaker (again in varying degrees) to some future course of action. Using $C$ for the members of this class, generally we have the following symbolism:

$$
C \uparrow I(S \text { does } A)
$$

The direction of fit is world-to-words and the sincerity condition is intention. The propositional content is always that the speaker $S$ does some future action $A$. Since the direction of fit is the same for commissives and directives, it would give us a more elegant taxonomy if we could show that they are really members of the same category. I am unable to do this, because whereas the point of a promise is to commit the speaker to doing something (and not necessarily to try to get himself to do it), the point of a request is to try to get the hearer to do something (and not necessarily to commit or obligate him to do it). In order to assimilate the two categories, one would have to show that promises are really a species of requests to oneself (this has been suggested to me by Julian Boyd) or alternatively one would have to show that requests placed the hearer under an obligation (this has been suggested to me by William Alston and John Kearns). I have been unable to make either of these analyses work and am left with the inelegant solution of two separate categories with the same direction of fit.

A fourth category I shall call

Expressives. The illocutionary point of this class is to express the psychological state specified in the sincerity condition about a state of affairs specified in the propositional content. The paradigms of expressive verbs are "thank," "congratulate," "apologize," "condole," "deplore," and "welcome." Notice that in expressives there is no direction of fit.

${ }^{\circ}$ Questions are directives, since they are attempts to get the hearer to perform a speech act.
A 'TAXONOMY OF IL.LOCUTIONARY ACTS

In performing an expressive, the speaker is neither trying to get the world to match the words nor the words to match the world; rather the truth of the expressed proposition is presupposed. Thus, for example, when I apologize for having stepped on your toe, it is not my purpose either to claim that your toe was stepped on nor to get it stepped on. This fact is neatly reflected in the syntax (of English) by the fact that the paradigm expressive verbs in their performance occurrence will not take that clauses but require a gerund nominalization transformation (or some other nominal). One cannot say:

* I apologize that I stepped on your toe;

rather the correct English is

I apologize for stepping on your toe.

Similarly, one cannot have

* I congratulate you that you won the race

nor

* I thank you that you paid me the money.

One must have

I congratulate you on winning the race (congratulations on winning the race).

I thank you for paying me the money (thanks for paying me the money).

These syntactical facts, I suggest, are consequences of the fact that there is in general no direction of fit in expressives. The truth of the proposition expressed in an expressive is presupposed. The symbolization of this class therefore must proceed as follows:

$$
E_{\phi}(P)(S / H+\text { property })
$$

where $E$ indicates the illocutionary point common to all expressives, $\phi$ is the null symbol indicating no direction of fit, $(P)$ is a variable ranging over the different possible psychological states expressed in the performance of the illocutionary acts in this class, and the propositional content ascribes some property (not necessarily an action) to either $S$ or $H$. I can congratulate you not only on your winning the race, but also on your good looks or on your son's winning the race. The property specified in the propositional content of an expressive must, however, 
John R. Searle

be related to $S$ or $H$. I cannot without some very special assumptions congratulate you on Newton's first law of motion.

It would be economical if we could include all illocutionary acts in these four classes and would lend some further support to the general pattern of analysis adopted in Speech Acts, but it seems to me it is still not complete. There is still left an important class of cases, where the state of affairs represented in the proposition expressed is realized or brought into existence by the illocutionary-force indicating device, cases where one brings a state of affairs into existence by declaring it to exist, cases where, so to speak, "saying makes it so." Examples of these cases are "I resign," "You're fired," "I excommunicate you," "I christen this ship the battleship Missouri," "I appoint you chairman," and "War is hereby declared." These cases were presented as paradigms in the very earliest discussions of performatives, but it seems to me they are still not adequately described in the literature and their relation to other kinds of illocutionary acts is usually misunderstood. Let us call this class

Declarations. It is the defining characteristic of this class that the successful performance of one of its members brings about the correspondence between the propositional content and reality; successful performance guarantees that the propositional content corresponds to the world: if I successfully perform the act of appointing you chairman, then you are chairman; if I successfully perform the act of nominating you as candidate, then you are a candidate; if I successfully perform the act of declaring a state of war, then war is on; if I successfully perform the act of marrying you, then you are married.

The surface syntactical structure of many sentences used to perform declarations conceals this point from us because in them there is no surface syntactical distinction between propositional content and illocutionary force. Thus "You're fired" and "I resign" do not seem to permit a distinction between illocutionary force and propositional content, but I think in fact that in their use to perform declarations their semantic structure is:

I declare: your employment is (hereby) terminated.

I declare: my position is (hereby) terminated.

Declarations bring about some alternation in the status or condition of the referred to object or objects solely in virtue of the fact that the declaration has been successfully performed. This feature of declarations
A TAXONOMY OF II.LOCUTIONARY ACTS

distinguishes them from the other categories. In the history of the discussion of these topics since Austin's first introduction of his distinction between performatives and constatives, this feature of declarations has not been properly understood. The original distinction between constatives and performatives was supposed to be a distinction between utterances which are sayings (constatives: statements, assertions, etc.) and utterances which are doings (performatives: promises, bets, warnings, etc.). What I am calling declarations were included in the class of performatives. The main theme of Austin's mature work, How to Do Things with Words, is that this distinction collapses. Just as saying certain things constitutes getting married (a "performative") and saying certain things constitutes making a promise (another "performative"), so saying certain things constitutes making a statement (supposedly a "constative"). As Austin saw, but as many philosophers still fail to see, the parallel is exact. Making a statement is as much performing an illocutionary act as making a promise, a bet, a warning, or what have you. Any utterance will consist in performing one or more illocutionary acts.

The illocutionary-force indicating device in the sentence operates on the propositional content to indicate among other things the direction of fit between the propositional content and reality. In the case of representatives the direction of fit is words-to-world; in the case of directives and commissives it is world-to-words; in the case of expressives there is no direction of fit carried by the illocutionary force because the existence of fit is presupposed. The utterance can't get off the ground unless there already is a fit. But now with the declarations we discover a very peculiar relation. The performance of a declaration brings about a fit by its very successful performance. How is such a thing possible?

Notice that all of the examples we have considered so far involve an extra-linguistic institution, a system of constitutive rules in addition to the constitutive rules of language, in order that the declaration may be successfully performed. The mastery of those rules which constitute linguistic competence by the speaker and hearer is not in general sufficient for the performance of a declaration. In addition there must exist an extra-linguistic institution and the speaker and hearer must occupy special places within this institution. It is only given such institutions as the church, the law, private property, the state, and a special position of the speaker and hearer within these institutions that one can excommunicate, appoint, give and bequeath one's possessions, or declare war. 
John R. Searle

The only exceptions to the principle that every declaration requires an extra-linguistic institution are those declarations that concern language itself, ${ }^{7}$ as for example when one says, "I define, abbreviate, name, call, or dub." Austin sometimes talks as if all performatives (and in the general theory, all illocutionary acts) required an extra-linguistic institution, but this is plainly not the case. Declarations are a very special category of speech acts. We shall symbolize their structure as follows:

$$
D \uparrow \phi(p)
$$

where $\mathrm{D}$ indicates the declarational illocutionary point; the direction of fit is both words-to-world and world-to-words because of the peculiar character of declarations; there is no sincerity condition, hence we have the null symbol in the sincerity condition slot; and we employ the usual propositional variable $p$.

The reason there has to be a relation-of-fit arrow here at all is that declarations do attempt to get language to match the world. But they do not attempt to do it either by describing an existing state of affairs (as do representatives) or by trying to get someone to bring about a future state of affairs (as do directives and commissives).

Some members of the class of declarations overlap with members of the class of representatives. This is because in certain institutional situations we not only ascertain the facts but we need an authority to lay down a decision as to what the facts are after the fact-finding procedure has been gone through. The argument must eventually come to an end and issue in a decision, and it is for this reason that we have judges and umpires. Both the judge and the umpire make factual claims: "you are out," "you are guilty." Such claims are clearly assessable in the dimension of word-world fit. Was he really tagged off base? Did he really commit the crime? They are assessable in the word-to-world dimension. But at the same time both have the force of declarations. If the umpire calls you out (and is upheld on appeal), then for baseball purposes you are out regardless of the facts in the case, and if the judge declares you guilty (on appeal), then for legal purposes you are guilty. There is nothing mysterious about these cases. Institutions characteristically require illocutionary acts to be issued by authorities of various kinds which have the force of declarations. Some institutions require

"Another rather special class of exceptions concerns the supernatural. When God says "Let there be light," that is a declaration.

\section{A TAXONOMY OF HLLOCUTIONARY ACTS}

representative claims to be issued with the force of declarations in order that the argument over the truth of the claim can come to an end somewhere and the next institutional steps which wait on the settling of the factual issue can proceed: the prisoner is released or sent to jail, the side is retired, a touchdown is scored. The members of this class we may dub "representative declarations." Unlike the other declarations, they share with representatives a sincerity condition. The judge, jury, and umpire can, logically speaking, lie, but the man who declares war or nominates you cannot lie in the performance of his illocutionary act. The symbolism for the class of representative declarations, then, is this:

$$
D_{r} \downarrow \downarrow B(p)
$$

where $D_{r}$ indicates the illocutionary point of issuing a representative with the force of a declaration, the first arrow indicates the representative direction of fit, the second indicates the declarational direction of fit, the sincerity condition is belief, and the $p$ represents the propositional content.

\section{Some Syntactical Aspects of the Classification}

So far, I have been classifying illocutionary acts and have used facts about verbs for evidence and illustration. In this section I want to discuss explicitly some points about English syntax. If the distinctions marked in section IV are of any real significance, they are likely to have various syntactical consequences, and I now propose to examine the deep structure of explicit performative sentences in each of the five categories; that is, I want to examine the syntactical structure of sentences containing the performative occurrence of appropriate illocutionary verbs appropriate to each of the five categories. Since all of the sentences we will be considering will contain a performative verb in the main clause, and a subordinate clause, I will abbreviate the usual tree structures in the following fashion: The sentence, for example, "I predict John will hit Bill," has the deep structure shown in the accompanying diagram. I will simply abbreviate this as: "I predict + John will hit Bill." Parentheses will be used to mark optional elements or elements that are obligatory only for restricted classes of the verbs in question. Where there is a choice of one of two elements, I will put a stroke between the elements, for example, "I/you." 
John R. Searle

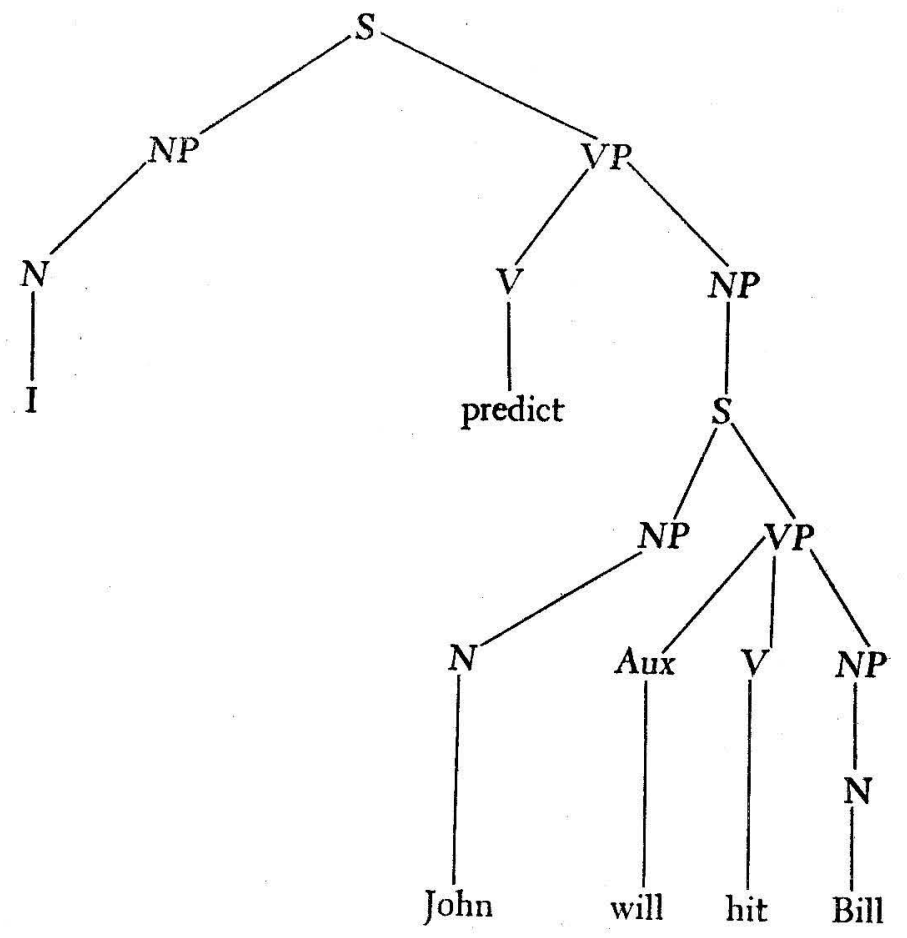

Representatives. The deep structure of such paradigm representative sentences as "I state that it is raining" and "I predict he will come" is simply,

$$
\text { I verb (that) }+S \text {. }
$$

This class, as a class, provides no further constraints; though particular verbs may provide further constraints on the lower node $S$. For example, "predict" requires that an Aux in the lower $S$ must be future or at any rate cannot be past. Such representative verbs as "describe," "call," "classify," and "identify" take a different syntactical structure, similar to many verbs of declaration, and I shall discuss them later.

Directives. Such sentences as "I order you to leave" and "I command you to stand at attention" have the following deep structure:

$$
\text { I verb you + you Fut Vol Verb (NP) (Adv). }
$$

"I order you to leave" is thus the surface structure realization of "I order you + you will leave" with equi NP deletion of the repeated "you." Notice that an additional syntactical argument for my including "dare,"

\section{A TAXONOMY OF ILLOCUTIONARY ACTS}

"defy," and "challenge," in my list of directive verbs and objecting to Austin's including them with "apologize," "thank," "congratulate," etc., is that they have the same syntactical form as do the paradigm directive verbs "order," "command," and "request." Similarly, "invite" and "advise" (in one of its senses) have the directive syntax. "Permit" also has the syntax of directives, though giving permission is not strictly speaking trying to get someone to do something; rather it consists in removing antecedently existing restrictions on his doing it.

Commissives. Such sentences as "I promise to pay you the money" and "I pledge allegiance to the flag" and "I vow to get revenge" have the deep structure

$$
\text { I verb (you) + I Fut Vol Verb (NP) (Adv). }
$$

Thus "I promise to pay you the money" is the surface structure realization of "I promise you + I will pay you the money," with equi NP deletion of the repeated "I." We hear the difference in syntax between "I promise you to come on Wednesday" and "I order you to come on Wednesday" as being that "I" is the deep structure subject of "come" in the first and "you" is the deep structure subject of "come" in the second, as required by the verbs "promise" and "order" respectively. Notice that not all of the paradigm commissives have "you" as an indirect object of the performative verb. In the sentence "I pledge allegiance to the flag" the deep structure is not "I pledge to you flag + I will be allegiant." It is

$$
\text { I pledge }+ \text { I will be allegiant to the flag. }
$$

Whereas there are purely syntactical arguments that such paradigm directive verbs as "order" and "command," as well as the imperative mood, require "you" as the deep structure subject of the lower node $S$, I do not know of any purely syntactical argument to show that commissives require " $\mathrm{I}$ " as the deep structure subject on their lower node $S$. Semantically, indeed, we must interpret such sentences as "I promise that Henry will be here on Wednesday" as meaning

I promise that I will see to it that Henry will be here next Wednesday,

insofar as we interpret the utterance as a genuine promise, but I know of no purely syntactical arguments to show that the deep structure of the former sentence contains the italicized elements in the latter. 


\section{John R. Scarle}

Expressives. As I mentioned earlier, expressives characteristically require a gerund transformation of the verb in the lower node $S$. We say:

\section{I apologize for stepping on your toe,}

I congratulate you on winning the race,

I thank you for giving me the money,

The deep structure of such sentences is:

I verb you $+I /$ you $V P \Rightarrow$ Gerund Nom.

And, to repeat, the explanation of the obligatory gerund is that there is no direction of fit. The forms that standardly admit of questions concerning direction of fit, that clauses and infinitives, are impermissible. Hence, the impossibility of

* I congratulate you that you won the race,

* I apologize to step on your toe.

However, not all of the permissible nominalization transformations are gerunds; the point is only that they must not produce that clauses or infinitive phrases; thus, we can have either

I apologize for behaving badly,

or

I apologize for my bad behavior,

but not

* I apologize that I behaved badly,

* I apologize to behave badly.

Before considering declarations, I want now to resume discussion of those representative verbs which have a different syntax from the paradigms above. I have said that the paradigm representatives have the syntactical form

$$
\text { I verb (that) }+S \text {. }
$$

But if we consider such representative verbs as "diagnose," "call," and "describe," as well as "class," "classify," and "identify," we find that they do not fit this pattern at all. Consider "call," "describe," and "diagnose," in such sentences as

I call him a liar,
I diagnose his case as appendicitis,

I describe John as a l'ascist.

and in general the form of this is

I verb $N P_{1}+N P_{1}$ be pred.

One cannot say

* I call that he is a liar,

* I diagnose that his case is appendicitis

(perversely, some of my students find this form acceptable),

* I describe that John is a Fascist.

There seems, therefore, to be a very severe set of restrictions on an important class of representative verbs which is not shared by the other paradigms. Would this justify us in concluding that these verbs were wrongly classed as representatives along with "state," "assert," "claim," and "predict" and that we need a separate class for them? I have heard it argued that the existence of these verbs substantiates Austin's claim that we require a separate class of verdictives distinct from expositives, but that would surely be a very curious conclusion to draw since Austin lists most of the verbs we mentioned above as expositives. He includes "describe," "class," "identify," and "call" as expositives and "diagnose" and "describe" as verdictives. A common syntax of many verdictives and expositives would hardly warrant the need for verdictives as a separate class. But leaving aside Austin's taxonomy, the question still arises, do we require a separate semantic category to account for these syntactical facts? I think not. I think there is a much simpler explanation of the distribution of these verbs. Often, in representative discourse, we focus our attention on some topic of discussion. The question is not just what is the propositional content we are asserting, but what do we say about the object(s) referred to in the propositional content: not just what do we state, claim, characterize, or assert, but how do we describe, call, diagnose, or identify it, some previously referred-to topic of discussion. When, for example, there is a question of diagnosing or describing, it is always a question of diagnosing a person or his case, of describing a landscape or a party or a person, etc. These representative illocutionary verbs give us a device for isolating topics from what is said about topics. But this very genuine syntactical difference does not mark a semantic 


\section{John R. Searle}

difference big enough to justify the formation of a separate category. Notice in support of my argument here that the actual sentences in which the describing, diagnosing, etc., is done are seldom of the explicit perfomative type, but rather are usually in the standard indicative forms which are so characteristic of the representative class.

\section{Utterances of:}

He is a liar,

He has appendicitis,

$\mathrm{He}$ is a Fascist,

are all characteristically statements, in the making of which we call, diagnose, and describe, as well as accuse, identify, and characterize. I conclude then that there are typically two syntactical forms for representative illocutionary verbs: one of which focuses on propositional content, the other on the object(s) referred to in the propositional content, but both of which are semantically representatives.

Declarations. I mention the syntactical form

$$
\text { I verb } N P_{1}+N P_{1} \text { be pred }
$$

both to forestall an argument for erecting a separate semantic category for them and because many verbs of declaration have this form. Indeed, there appear to be several different syntactical forms for explicit performatives of declaration. I believe the following three classes are the most important.

1. I find you guilty as charged.

I now pronounce you man and wife.

I appoint you chairman.

2. War is hereby declared.

I declare the meeting adjourned.

3. You're fired.

I resign.

I excommunicate you.

The deep syntactical structure of these three, respectively, is as follows:

$$
1 . I \text { verb } N P_{1}+N P_{1} \text { be pred. }
$$

Thus in our examples we have

I find you + you be guilty as charged.

I pronounce you + you be man and wife.

\section{A TAXONOMY OF ILLOCUTIONARY ACTS}

I appoint you + you be chairman.

2. I declare $+S$.

Thus in our examples we have

I/we (hereby) declare + a state of war exists.

I declare + the meeting be adjourned.

This form is the purest form of the declaration: the speaker in authority brings about a state of affairs specified in the propositional content by saying in effect, I declare the state of affairs to exist. Semantically, all declarations are of this character, though in class 1 the focusing on the topic produces an alteration in the syntax which is exactly the same syntax as we saw in such representative verbs as "describe," "characterize," "call," and "diagnose," and in class 3 the syntax conceals the semantic structure even more.

3. The syntax of these is the most misleading. It is simply I verb $(N P)$

as in our examples,

\section{I fire you.}

I resign.

I excommunicate you.

The semantic structure of these, however, seems to me the same as class 2. "You're fired," if uttered as performance of the act of firing someone and not as a report means

I declare + Your job is (hereby) terminated.

Similarly, "I hereby resign" means

I hereby declare + My job is (hereby) terminated.

"I excommunicate you" means

I declare + Your membership in the church is (hereby) terminated.

The explanation for the bemusingly simple syntactical structure of these sentences seems to me to be that we have some verbs which in their performative occurrence encapsulate both the declarative force and the propositional content. 


\section{John R. Searle \\ VI. Conclusions}

We are now in a position to draw certain general conclusions.

1. Many of the verbs we call illocutionary verbs are not markers of illocutionary point but of some other feature of the illocutionary act. Consider "insist" and "suggest." I can insist that we go to the movies or I can suggest that we go to the movies; but I can also insist that the answer is found on page 16 or I can suggest that it is found on page 16. The first pair are directives, the second, representatives. Does this show that insisting and suggesting are different illocutionary acts altogether from representatives and directives, or perhaps that they are both representatives and directives? I think the answer to both questions is no. Both "insist" and "suggest" are used to mark the degree of intensity with which the illocutionary point is presented. They do not mark a separate illocutionary point at all. Similarly, "announce," "present," and "confide" do not mark separate illocutionary points but rather the style or manner of performance of an illocutionary act. Paradoxical as it may sound, such verbs are illocutionary verbs, but not names of kinds of illocutionary acts. It is for this reason, among others, that we must carefully distinguish a taxonomy of illocutionary acts from one of illocutionary verbs.

2. In section IV I tried to classify illocutionary acts and in section V I tried to explore some of the syntactical features of the verbs denoting member of each of the categories. But I have not attempted to classify illocutionary verbs. If one did so, I believe the following would emerge.

a. First, as just noted, some verbs do not mark illocutionary point at all, but some other feature, e.g., "insist," "suggest," "announce," "confide," "reply," "answer," "interject," "remark," "ejaculate," and "interpose."

b. Many verbs mark illocutionary point plus some other feature, e.g., "boast," "lament," "threaten," "criticize," "accuse," and "warn" all add the feature of goodness or badness to their primary illocutionary point.

c. Some few verbs mark more than one illocutionary point; for example, a protest involves both an expression of disapproval and a petition for change.

Promulgating a law has both a declarational status (the propositional content becomes law) and a directive status (the law is directive in in- tent). The verbs of representative declaration fall into this class of verbs with two illocutionary points.

d. Some few verbs can take different illocutionary points in different utterances. Consider "warn" and "advise." Notice that both of thesc take either the directive syntax or the representative syntax. Thus

I warn you to stay away from my wife!

I warn you that the bull is about to charge.

I advise you to leave.

Passengers are hereby advised that the train will be late.

(directive) (representative) (directive)

(representative)

Correspondingly, it seems to me, that warning and advising may be either telling you that something is the case (with relevance to what is or is not in your interest) or telling you to do something about it (because it is or is not in your interest). They can also be, but need not be, both at once.

3. The most important conclusion to be drawn from this discussion is this. There are not, as Wittgenstein (on one possible interpretation) and many others have claimed, an infinite or indefinite number of language games or uses of language. Rather, the illusion of limitless uses of language is engendered by an enormous unclarity about what constitutes the criteria for delimiting one language game or use of language from another. If we adopt illocutionary point as the basic notion on which to classify uses of language, then there are a rather limited number of basic things we do with language: we tell people how things are, we try to get them to do things, we commit ourselves to doing things, we express our feelings and attitudes, and we bring about changes through our utterances. Often, we do more than one of these at once in the same utterance. 